BMC

Veterinary Research

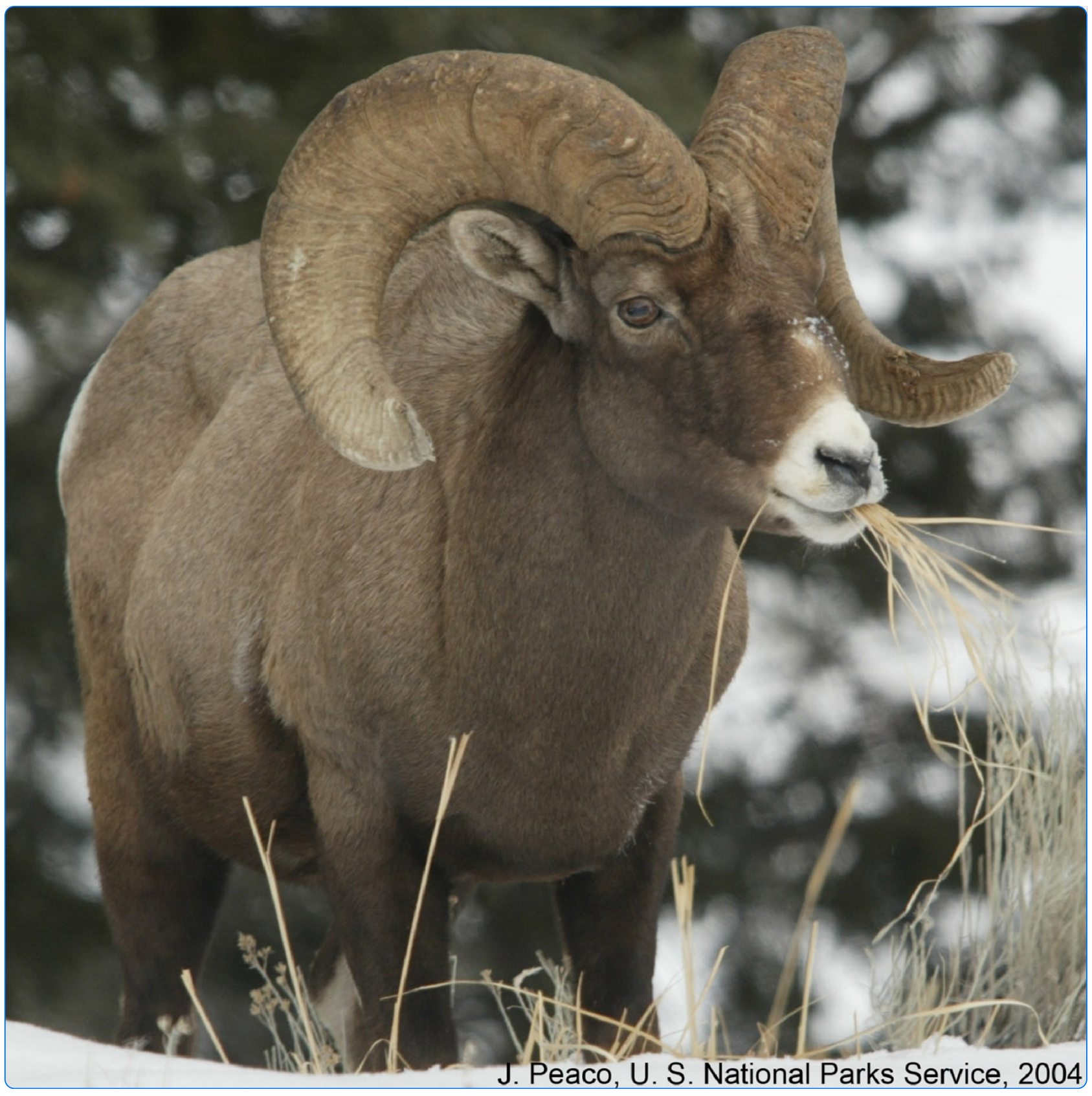

In vitro prion protein conversion suggests risk of bighorn sheep (Ovis canadensis) to transmissible spongiform encephalopathies

Morawski et al. 


\title{
In vitro prion protein conversion suggests risk of bighorn sheep (Ovis canadensis) to transmissible spongiform encephalopathies
}

\author{
Aaron R Morawski ${ }^{1,2,4}$, Christina M Carlson ${ }^{2,3}$, Haeyoon Chang ${ }^{2}$ and Christopher J Johnson ${ }^{2 *}$
}

\begin{abstract}
Background: Transmissible spongiform encephalopathies (TSEs) affect both domestic sheep (scrapie) and captive and free-ranging cervids (chronic wasting disease; CWD). The geographical range of bighorn sheep (Ovis canadensis; BHS) overlaps with states or provinces that have contained scrapie-positive sheep or goats and areas with present epizootics of CWD in cervids. No TSEs have been documented in BHS, but the susceptibility of this species to TSEs remains unknown.

Results: We acquired a library of BHS tissues and found no evidence of preexisting TSEs in these animals. The prion protein gene (Prnp) in all BHS in our library was identical to scrapie-susceptible domestic sheep $\left(A^{136} R^{154} Q^{171}\right.$ genotype). Using an in vitro prion protein conversion assay, which has been previously used to assess TSE species barriers and, in our study appears to recollect known species barriers in mice, we assessed the potential transmissibility of TSEs to BHS. As expected based upon Prnp genotype, we observed BHS prion protein conversion by classical scrapie agent and evidence for a species barrier between transmissible mink encephalopathy (TME) and BHS. Interestingly, our data suggest that the species barrier of BHS to white-tailed deer or wapiti CWD agents is likely low. We also used protein misfolding cyclic amplification to confirm that CWD, but not TME, can template prion protein misfolding in $A^{136} R^{154} Q^{171}$ genotype sheep.

Conclusions: Our results indicate the in vitro conversion assay used in our study does mimic the species barrier of mice to the TSE agents that we tested. Based on Prnp genotype and results from conversion assays, BHS are likely to be susceptible to infection by classical scrapie. Despite mismatches in amino acids thought to modulate prion protein conversion, our data indicate that $A^{136} R^{154} Q^{171}$ genotype sheep prion protein is misfolded by CWD agent, suggesting that these animals could be susceptible to CWD. Further investigation of TSE transmissibility to BHS, including animal studies, is warranted. The lack of reported TSEs in BHS may be attributable to other host factors or a lack of TSE surveillance in this species.
\end{abstract}

Keywords: Bighorn sheep, Scrapie, Chronic wasting disease, Transmissible mink encephalopathy, Species barrier

\section{Background}

Prior to human settlement, bighorn sheep (Ovis canadensis; BHS) were widely distributed and abundant in western North America [1]. Overharvest, habitat loss and disease have contributed to population declines and modern-day numbers of BHS are thought to be reduced by more than 90\% compared to those during pre-settlement times [1]. More than half of existing BHS populations are the result

\footnotetext{
* Correspondence: cijohnson@usgs.gov

2USGS National Wildlife Health Center, Madison, WI, USA

Full list of author information is available at the end of the article
}

of restoration efforts and certain subspecies are presently endangered or have gone extinct [2,3]. Disease continues to be a major obstacle to BHS recovery [1]. The transfer of pathogens, such as Mannheimia haemolytica, from domestic sheep (Ovis aires) to BHS and between BHS herds has caused numerous mortality events and has been modeled under experimental conditions [4-6]. While less well characterized, cervids like white-tailed deer (Odocoileus virginianus), mule deer (O. hemionus), wapiti (American elk; Cervus canadensis) or moose (Alces alces) may also share disease with BHS [7].

\section{Ciomed Central}

(c) 2013 Morawski et al.; licensee BioMed Central Ltd. This is an Open Access article distributed under the terms of the Creative Commons Attribution License (http://creativecommons.org/licenses/by/2.0), which permits unrestricted use, distribution, and reproduction in any medium, provided the original work is properly cited. 
Domestic sheep and free-ranging and farmed cervids are all affected by transmissible spongiform encephalopathies (TSEs, prion diseases) [8]. Scrapie is a TSE of domestic sheep and goats that is endemic in many countries [9]. Chronic wasting disease (CWD) is an emerging prion disease that affects deer, wapiti and moose [10]. Since its identification in 1967, CWD has been detected in captive or free-ranging deer, wapiti or moose populations in at least 22 states, 2 Canadian provinces and South Korea. In captive populations, CWD can reach nearly $100 \%$ prevalence [11] and while the upper limit of CWD prevalence in freeranging populations is not yet known, some portions of Wyoming have recently observed $>50 \%$ prevalence [12]. Scrapie and CWD infectivity is shed from diseased animals, allowing transmission to naïve hosts [13]. Remarkably, scrapie and CWD infectivity shed into the environment persists for long periods of time (years to decades) and can cause disease when naïve animals are later exposed $[14,15]$. Direct contact with shed scrapie or CWD agent, as well as environmental sources of infectivity, are both plausible mechanisms of TSE transmission whereby new species, such as $\mathrm{BHS}$, could be exposed to disease. The range of BHS substantially overlaps with states and provinces known to have had recent scrapie outbreaks, areas where CWD is endemic in free-ranging cervids and captive cervid facilities where CWD has been found (Figure 1).

The infectious agent responsible for TSEs is thought to be a misfolded protein, termed a prion. During infection, the normal, host cellular prion protein $\left(\mathrm{PrP}^{\mathrm{C}}\right)$ is converted to a misfolded form ( $\mathrm{PrP}^{\mathrm{TSE}}$ ) that accumulates in the nervous system, is associated with disease and is a primary component of the infectious prion agent [16]. Proteinase K (PK) is used to discriminate between the two conformers of prion protein; $\mathrm{PrP}^{\mathrm{C}}$ is completely degraded following PK treatment whereas the protease cleaves only the $N$ terminus from $\operatorname{PrP}^{\mathrm{TSE}}$ and leaves an infectious core intact [17]. The presence of PK-resistant $\operatorname{PrP}\left(\mathrm{PrP}^{\mathrm{res}}\right)$ in a sample is a common diagnostic indicator of TSE infection [18].

For interspecies TSE transmission, the degree to which host $\operatorname{PrP}^{\mathrm{C}}$ matches the sequence of the infectious $\operatorname{PrP}^{\mathrm{TSE}}$ can be a key determinant in whether conversion will take place [19]. While animal challenges remain the most definitive measure of the susceptibility of a species to a TSE, a number of in vitro assays have been developed to assess the potential for interspecies TSE transmissions. Such assays typically assess the conversion of host $\operatorname{PrP}^{C}$ to a PK-resistant state when seeded by $\operatorname{PrP}^{\mathrm{TSE}}$. Cell-free conversion assays, protein misfolding cyclic amplification (PMCA) and the conversion efficiency ratio (CER) assay have all been used to assess TSE species barriers [20-23]. In the CER assay, two denatured $\operatorname{PrP}^{C}$ substrates are used in conversions [24]. One of the denatured substrates is processed at $\mathrm{pH} 7.4$ and a previous report indicates that only in the absence of a species barrier is the $\operatorname{PrP}^{C}$ in the

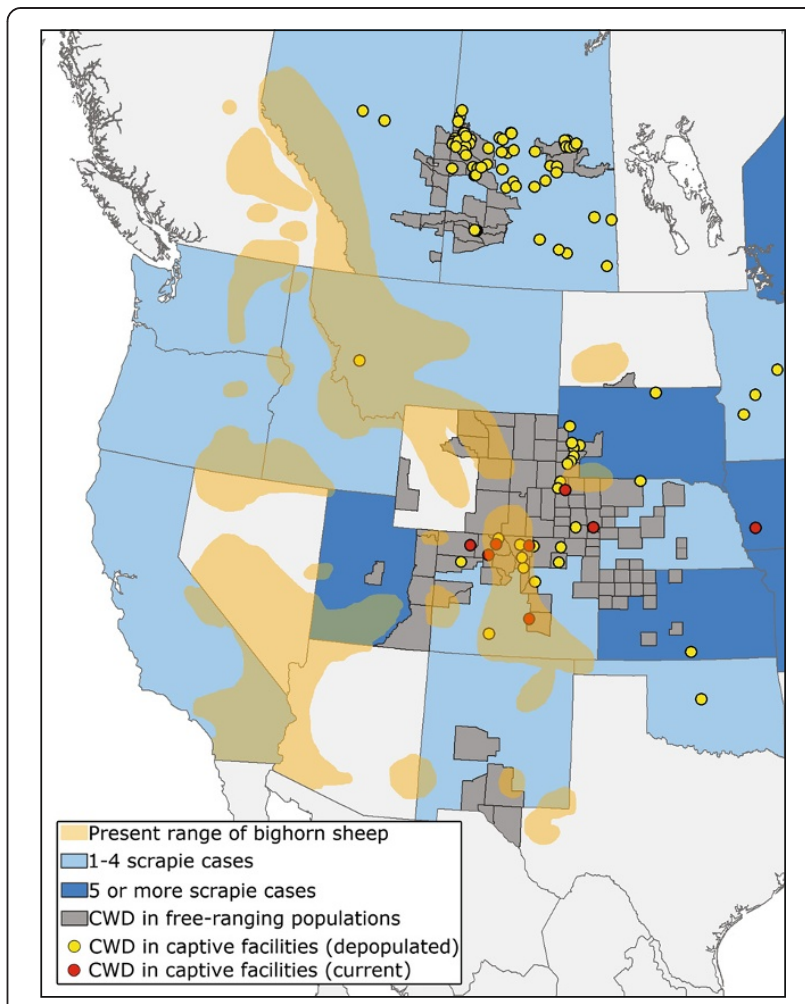

Figure 1 Overlap of bighorn sheep range with scrapie and chronic wasting disease (CWD). Orange regions represent the present range of bighorn sheep (data from Grand Slam/Ovis). Blue shading indicates either 1-4 (light blue) or 5 or more (dark blue) cases of scrapie in a state or province since October, 2008 (data from US Department of Agriculture and Scrapie Canada). Grey coloring represents areas where CWD has been identified in freeranging cervid populations. Yellow or red dots indicate CWD in depopulated or active captive facilities, respectively.

substrate converted to $\operatorname{PrP}^{\text {res }}$ by $\operatorname{PrP}^{\text {TSE }}$ [23]. The other $\mathrm{PrP}^{\mathrm{C}}$ substrate is processed at $\mathrm{pH} 3.5$ and can be converted to $\mathrm{PrP}^{\text {res }}$ following incubation with any species of $\mathrm{PrP}^{\mathrm{TSE}}$. Comparing $\operatorname{PrP}^{\mathrm{res}}$ levels in these two substrates provides a measure of the species barrier. Li et al. introduced this assay in an effort to predict the species barriers of numerous animals to wapiti CWD [23]. In the present manuscript, we assess the Prnp genotype of 28 BHS in a tissue library and find no evidence of TSE in these tissues. We confirm that the CER assay correctly predicts known species barriers of laboratory mice to various TSEs and go on to use this assay to assess $\operatorname{PrP}^{\mathrm{C}}$ conversion in BHS substrates by domestic sheep classical scrapie, transmissible mink encephalopathy (TME) and CWD.

\section{Results}

\section{Sequence analysis of BHS}

We isolated genomic DNA from 28 BHS in our tissue library and sequenced their prion protein gene (Prnp). A previous report and entry in GenBank (AAD48030.1) indicated that the prion protein from a group of $\mathrm{BHS}$ 
has the same amino acid sequence as scrapie-susceptible $\mathrm{A}^{136} \mathrm{R}^{154} \mathrm{Q}^{171}$ genotype domestic sheep [21]. Our results were identical to the previously published report and no amino acid changes were found in any BHS sequenced. An alignment of BHS prion protein with that of other species is shown in Figure 2 and the similarity between BHS, domestic sheep, white-tailed deer and wapiti prion proteins was $>95 \%$. The mink, laboratory mouse and Syrian hamster prion proteins are more divergent.

\section{Screening BHS tissues for TSEs}

The sequence identity between domestic sheep and BHS prion proteins allowed us to use reagents tested in domestic sheep for analysis of prion protein in BHS tissues. We tested the BHS in our tissue library for evidence of preexisting TSEs by examining PK-treated brain homogenates for the presence of $\operatorname{PrP}^{\text {res }}$ by immunoblotting (Figure 3A). Samples of brain were taken from the obex region of the medulla oblongata, homogenized, digested with PK or mock digested and immunoblotted. No PrP $\mathrm{P}^{\mathrm{res}}$ was detected in any BHS sample, suggesting the animals were free of TSE. The $\operatorname{PrP}^{C}$ signal observed in the nonPK-digested immunoblot samples was generally abundant (Figure 3A), indicating a lack of proteolysis in our tissue samples and encouraging our use of these tissues as substrates for in vitro conversion assays. To test the sensitivity of our immunoblotting procedures, we prepared dilutions of brain homogenate from a domestic sheep that was clinically-ill with classical scrapie in BHS brain homogenate and PK treated the mixtures. We

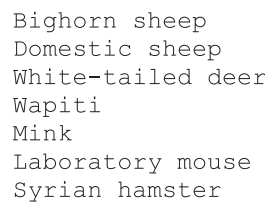

1

MVKSH I GSWI LVLFVAMWSDVGLCKKRPKPGGGWNTGGSRYPGQGS PGGNRYPPOGGGGW MVKSHIGSWILVLFVAMWSDVGLCKKRPKPGGGWNTGGSRYPGQGS PGGNRYPPOGGGGW MVKSHIGSWILVLFVAMWSDVGLCKKRPKPGGGWNTGGSRYPGQGSPGGNRYPPQGGGGW MVKSHIGSWILVLFVAMWSDVGLCKKRPKPGGGWNTGGSRYPGQGSPGGNRYPPQGGGGW MVKSHI GSWLLVLFVATWSDI GFCKKWPKPGGGWNTGGSRYPGOGSPGGNRYPPOGGGGW --MANLGYWLLALFVTMWTDVGLCKKRPKPGG-WNTGGSRYPGQGSPGGNRYPPQGG-TW --MANLSYWLLALFVATWTDVGLCKKRPKPGG-WNTGGSRYPGQGSPGGNRYPPQGGGTW

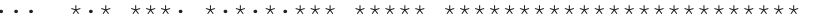

61 GQPHGGGWGQPHGGGWGOPHGGGWGQPHGGGGWGOGG-SHSOWNKPSKPKTNMKHVAGAA GQPHGGGWGQPHGGGWGQPHGGGWGQPHGGGGWGQGG-SHSQWNKP SKPKTNMKHVAGAA GQPHGGGWGQPHGGGWGQPHGGGWGQPHGGGGWGQGG-THSQWNKP SKPKTNMKHVAGAA GOPHGGGWGOPHGGGWGOPHGGGWGOPHGGGGWGOGG-THSOWNKPSKPKTNMKHVAGAA GQPHGGGWGQPHGGGWGQPHGGGWGQPHGGGGWGQGGGSHGQWGKPSKPKTNMKHVAGAA GQPHGGGWGQPHGGSWGQPHGGSWGQPHGGG-WGQGGGTHNQWNKP SKPKTNLKHVAGAA GQPHGGGWGQPHGGGWGQPHGGGWGQPHGGG-WGQGGGTHNQWNKPNKPKTSMKHMAGAA

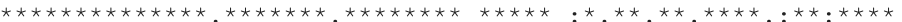

120

AGAVVGGLGGYMLGSAMSRPLTHFGNDYEDRYYRENMYRYPNOVYYRPVDOYSNONNFV AAGAVVGGLGGYMLGSAMSRPLIHFGNDYEDRYYRENMYRYPNQVYYRPVDQYSNQNNFV AAGAVVGGLGGYMLGSAMSRPLIHFGNDYEDRYYRENMYRYPNQVYYRPVDQYNNQNTFV AAGAVVGGLGGYMLGSALSRPLIHFGNDYEDRYYRENMYRYPNOVYYRPVDOYNNONTFV AAGAVVGGLGGYMLGSAMSRPLIHFGNDYEDRYYRENMYRYPNQVYYKPVDQYSNQNNFV AAGAVVGGLGGYMLGSAMSRPMI HFGNDWEDRYYRENMYRYPNQVYYRPVDQYSNQNNFV AAGAVVGGLGGYMLGSAMSRPMLHFGNDWEDRYYRENMNRY PNQVYYRPVDQYNNQNNFV

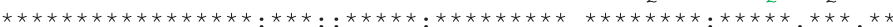

180

HDCVNITVKQHTVTTTTKGENFTETDIKIMERVVEQMCITQYQRESQAYY--QRGASVIL HDCVNITVKQHTVTTTTKGENFTETDIKIMERVVEQMCITQYQRESQAYY--QRGASVIL HDCVNITVKQHTVTTTTKGENFTETDIKMMERVVEQMCITQYQRESQAYY--QRGASVIL HDCVNITVKOHTVTTTTKGENFTETDIKMMERVVEQMCITQYQRESOAYY--QRGASVIL HDCVNITVKQHTVTTTTKGENFTETDMKIMERVVEQMCVTQYQRESEAYY--QKGASAIL HDCVNITIKQHTVTTTTKGENFTETDVKMMERVVEQMCVTQYQKESQAYYDGRRSSSTVL HDCVNITIKQHTVTTTTKGENFTETDVKMMERVVEQMCVTQYQKESQAYYDGRRSS -AVL

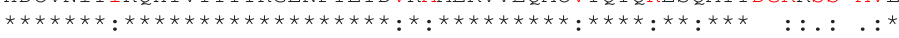

$$
240
$$

FSSPPVILLISFLIFLIVG FSSPPVILLISFLIFLIVG FSSPPVILLISFLIFLIVG FSSPPVILLISFLIFLIVG FSPPPVILLISLLILLIVG FSSPPVILLISELIFLIVG FSSPPVILLISELIFLIVG $\star_{*} * * * * * * * *, * * ; * * * *$

$\begin{array}{lr}\text { Homology to Bighorn sheep: } & 100 \% \\ \text { Homology to Bighorn sheep: } & 98 \% \\ \text { Homology to Bighorn sheep: } & 98 \% \\ \text { Homology to Bighorn sheep: } & 93 \% \\ \text { Homology to Bighorn sheep: } & 87 \% \\ \text { Homology to Bighorn sheep: } & 85 \%\end{array}$

Figure 2 Prion protein amino acid alignment of bighorn sheep, domestic sheep $\left(A^{136} R^{154} Q^{171}\right)$, white-tailed deer, wapiti, mink, laboratory mouse and hamster. Green letters indicate key amino acids for scrapie susceptibility. Red letters indicate mismatches. Below sequence the alignment, consensus symbols (* identical amino acids, amino acids with strongly similar properties, amino acids with weakly similar properties) are displayed. 


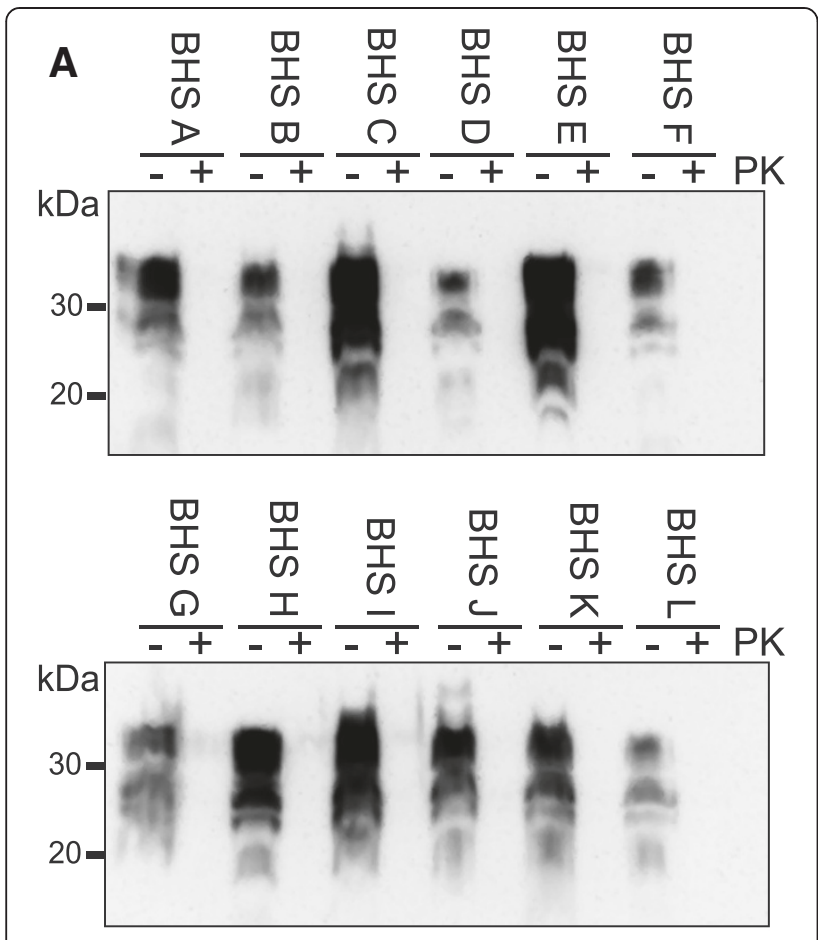

B

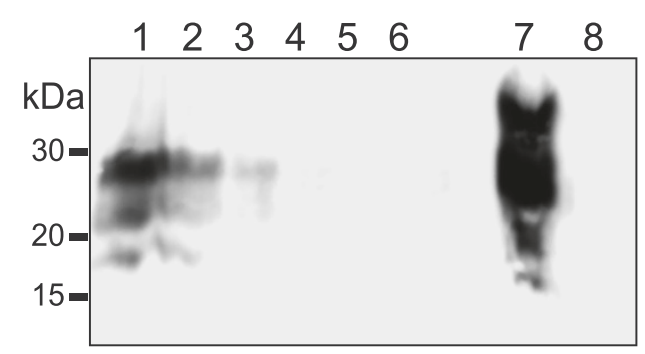

Figure 3 No evidence of proteinase K (PK)-resistant prion protein in bighorn sheep brain tissues. (A) Individual bighorn sheep (BHS) were given unique letters to identify them (A-L). The obex region of the medulla from each animal was collected, homogenized to $10 \% \mathrm{w} / \mathrm{V}$, a $25 \mu \mathrm{L}$ aliquot of each homogenate incubated in the presence of $50 \mathrm{\mu g} \cdot \mathrm{ml}^{-1}$ of proteinase $\mathrm{K}(+)$ or in the absence of PK (-) and then immunoblotted. Samples from the other BHS in our tissue library similarly did not have PK-resistant prion protein. (B) A dilution series of classical scrapie brain homogenate was prepared in BHS brain homogenate, incubated in the presence of 50 $\mu \mathrm{g} \cdot \mathrm{ml}^{-1}$ of proteinase $\mathrm{K}$ and immunoblotted. Scrapie dilution factors were 3, 10, 30, 100, 300 and 1000 (lanes 1-6). Lanes 7 and 8 represent nonproteinase $\mathrm{K}$-treated and proteinase $\mathrm{K}$-treated BHS brain homogenate in the absence of scrapie brain homogenate, respectively. Immunoblots used monoclonal antibody BAR 224.

found that we could detect scrapie $\operatorname{PrP}^{\text {res }}$ out to a dilution factor of 30 (Figure 3B), indicating that $\mathrm{PrP}^{\text {res }}$ levels in the BHS were below this threshold. As an additional control, we tested if we could detect $\operatorname{PrP}^{\mathrm{Sc}}$ in BHS brain tissues selected for use in conversion assays following three rounds of serial protein misfolding cyclic amplification. We did not detect any $\operatorname{PrP}^{\text {res }}$ in any amplified sample (data not presented).
Retropharyngeal lymph nodes are among the first sites where abnormal prion protein can be detected in some preclinical TSEs and testing this tissue is useful in diagnosing domestic sheep scrapie [25]. Despite no evidence of $\mathrm{PrP}^{\text {res }}$ in our library of BHS brain tissue, we screened retropharyngeal lymph nodes from the $28 \mathrm{BHS}$ using the BioRad TeSeE ELISA test, an assay commonly used to test domestic sheep for scrapie. We found no positive samples (data not shown), consistent with the idea that our BHS tissues do not harbor preexisting TSEs.

\section{Control conversion efficiency ratio (CER) studies}

The species barrier of laboratory mice to most TSEs is well-characterized [26]. For that reason, we began our investigations with the $\mathrm{CER}$ assay using mouse $\mathrm{PrP}^{\mathrm{C}}$ substrates and TSE agents that have been used in previous mouse bioassays. Specifically, we used the RML strain of mouse-passaged scrapie, an agent adapted to passage in mice [27], domestic sheep classical scrapie, an agent that can transmit to mice following a lengthy incubation period [27] and CWD and 263K strain of hamster-passaged scrapie, agents to which mice are minimally or not susceptible $[28,29]$.

We incubated mouse $\operatorname{PrP}^{\mathrm{C}}$ substrates with these TSE agents and assessed conversion of $\operatorname{PrP}^{\mathrm{C}}$ to $\operatorname{PrP}^{\text {res }}$ (Figure 4A). In mouse $\operatorname{PrP}^{\mathrm{C}}$ substrate denatured at $\mathrm{pH}$ 7.4, these TSE agents produced a range of $\mathrm{PrP}^{\mathrm{res}}$ levels whereas in the substrate denatured at $\mathrm{pH} 3.5, \operatorname{PrP}^{\text {res }}$ was found in all samples incubated with a TSE agent. The ratios comparing the $\mathrm{PrP}^{\mathrm{res}}$ levels in the $\mathrm{pH} 7.4$ and $\mathrm{pH}$ 3.5 substrates were independently examined at least three times and means +/- SD are shown in Figure 4B. The conversion ratios between $\mathrm{pH} 7.4$ and 3.5 substrates seeded by RML were approximately $100 \%$. Scrapie-induced conversion of the $\mathrm{pH} 7.4$ substrate was approximately $75 \%$ of the $\mathrm{pH} 3.5$ substrate and conversion of the $\mathrm{pH} 7.4$ substrate by either CWD or $263 \mathrm{~K}$ was minimal. A one-way analysis of variance did not find a significant difference between RML and scrapie or CWD and 263K conversion ratios. Conversion ratios of RML and scrapie were, however, significantly different from CWD and 263K.

\section{Experimental CER studies}

With evidence suggesting that $\operatorname{PrP}^{\mathrm{C}}$ in our BHS brain tissues was intact and present at detectable levels (Figure 3), and that the CER assay can reproduce mouse TSE species barriers (Figure 4), we generated CER assay substrates from BHS brain to assess the conversion of $\mathrm{BHS} \mathrm{PrP}^{\mathrm{C}}$ by TSE agents. We chose to assess domestic classical sheep scrapie because BHS and $\mathrm{A}^{136} \mathrm{R}^{154} \mathrm{Q}^{171}$ genotype domestic sheep share an identical Prnp sequence and selected isolates of CWD because of range overlap. Transmissible mink encephalopathy (TME) agent was used as a control because there are multiple sequence differences between 


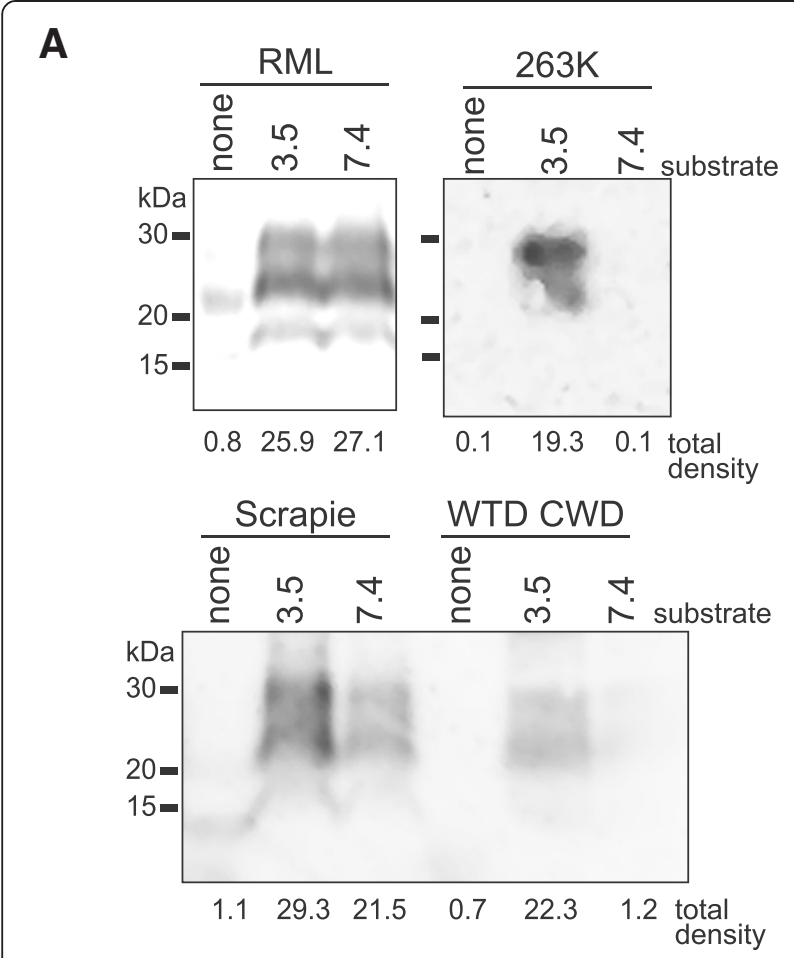

B

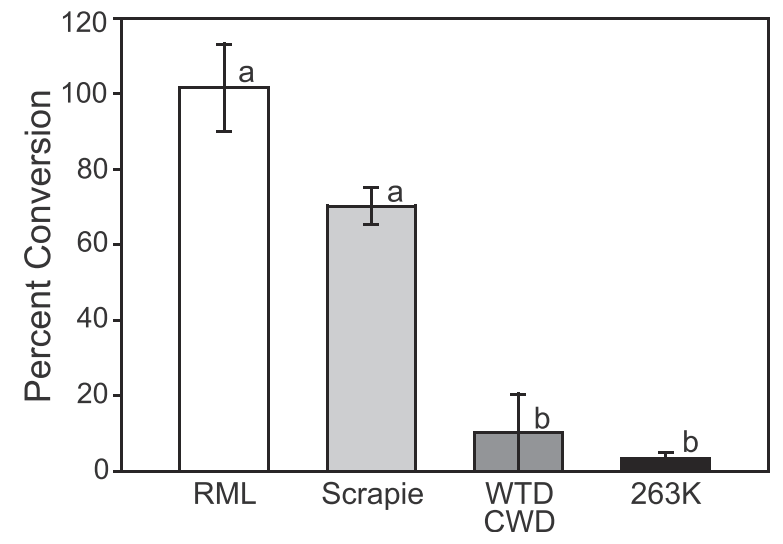

Figure 4 Conversion efficiency ratio (CER) assay using laboratory mouse substrate. (A) Mouse CER assay substrate prepared at either pH 7.4 or 3.5 was incubated with RML mouseadapted scrapie, domestic sheep classical scrapie, white-tailed deer (WTD) chronic wasting disease agent (CWD) or 263K strain of hamster-adapted scrapie. Control samples (labeled "none") contained only an equal amount of infectious agent and no mouse substrate.

Samples were analyzed for the presence of proteinase K-resistant prion protein by immunoblot with monoclonal antibody SAF 83. Raw densitometric values for each sample are displayed below each lane. (B) Bar graph indicating the average ratios (+/- standard deviation) between $\mathrm{pH} 7.4$ and 3.5 mouse substrates for each infectious agent based on at least three independent assay runs. Lower-case letters refer to statistically homogeneous subsets (analysis of variance with Tukey-Kramer minimum significance differences method; $p<0.05$ ). mink and BHS prion proteins (Figure 2) and because a previous study indicated limited transmissibility of TME to domestic sheep (Cheviot breed) with an extended incubation period (mean: $65 \mathrm{mo}$ ) and with only about $25 \%$ penetrance [29].

In Figure 5, we assessed conversion of $\mathrm{BHS} \operatorname{PrP}^{\mathrm{C}}$ to $\operatorname{PrP}^{\text {res }}$ by these various TSE agents. We found that domestic sheep classical scrapie induced $\mathrm{PrP}^{\mathrm{C}}$ to $\mathrm{PrP}^{\text {res }}$ conversion in BHS and domestic sheep $\mathrm{pH} 7.4$ substrates, as well as $\mathrm{pH} 3.5$ substrates (Figure 5A). In BHS samples, some $\operatorname{PrP}^{\text {res }}$ was detectable in $\mathrm{pH}$ 7.4 substrate incubated with TME agent, however the amount appeared somewhat diminished compared to the BHS pH 3.5 substrates (Figure 5B). In mink, TME agent caused $\operatorname{PrP}^{\mathrm{C}}$ to $\operatorname{PrP}^{\text {res }}$ conversion in both $\mathrm{pH}$ 7.4 and 3.5 samples. In BHS samples incubated with whitetailed deer CWD, PrP ${ }^{\text {res }}$ was detected in both $\mathrm{pH} 7.4$ and 3.5 substrates (Figure 5C). In Figure 5D, similar results were obtained using an isolate of CWD from a wapiti heterozygous methionine/leucine at position $132\left(\mathrm{M} / \mathrm{L}^{132}\right)$. Both isolates of CWD caused $\mathrm{PrP}^{\mathrm{C}}$ to $\mathrm{PrP}^{\text {res }}$ conversion in white-tailed deer (Figure 5C and D). Control samples of substrates prepared at $\mathrm{pH} 7.4$ and 3.5 for all species were run in the absence of TSE agents and $\mathrm{PrP}^{\text {res }}$ was not detected (Additional file 1).

We calculated CER values by evaluating $\operatorname{PrP}^{\text {res }}$ levels in the $\mathrm{pH} 7.4$ and 3.5 substrates for both the BHS and the native hosts for the TSEs we tested. We used data from at least three independently performed experiments and substrates prepared from three BHS, two domestic sheep, two mink and one white-tailed deer. Data for all of the average CER values +/- standard deviation are shown in Figure 6. We compared CER values for BHS to the normal hosts for the TSE using a Student's $t$-tests and found that only TME in BHS was significantly different $(\mathrm{t}=5.7517, \mathrm{df}=4, \mathrm{p}=0.0045)$.

\section{Protein misfolding cyclic amplification (PMCA)}

As a control for our results from the CER assay, we performed a limited PMCA study to investigate misfolding of sheep $\operatorname{PrP}^{\mathrm{C}}$ by $\operatorname{PrP}^{\mathrm{TSE}}$ from CWD and TME. We subjected dilutions of classical scrapie, white-tailed deer CWD and TME in $\mathrm{A}^{136} \mathrm{R}^{154} \mathrm{Q}^{171}$ genotype domestic sheep PMCA substrate to cyclic sonication (Additional file 2). Following $48 \mathrm{~h}$ of PMCA, we detected $\operatorname{PrP}^{\text {res }}$ in samples seeded with either sheep scrapie or CWD, but not in samples seeded with TME. Substrate subjected to PMCA but lacking TSE agent seed did not contain detectable $\operatorname{PrP}^{\mathrm{res}}$ and samples containing TSE agents that were not sonicated establish the background levels of $\mathrm{PrP}^{\mathrm{res}}$.

\section{Discussion}

Using the CER assay, we found evidence that this method recapitulates known species barriers of laboratory mice to TSEs and data to suggest that BHS could be susceptible to 


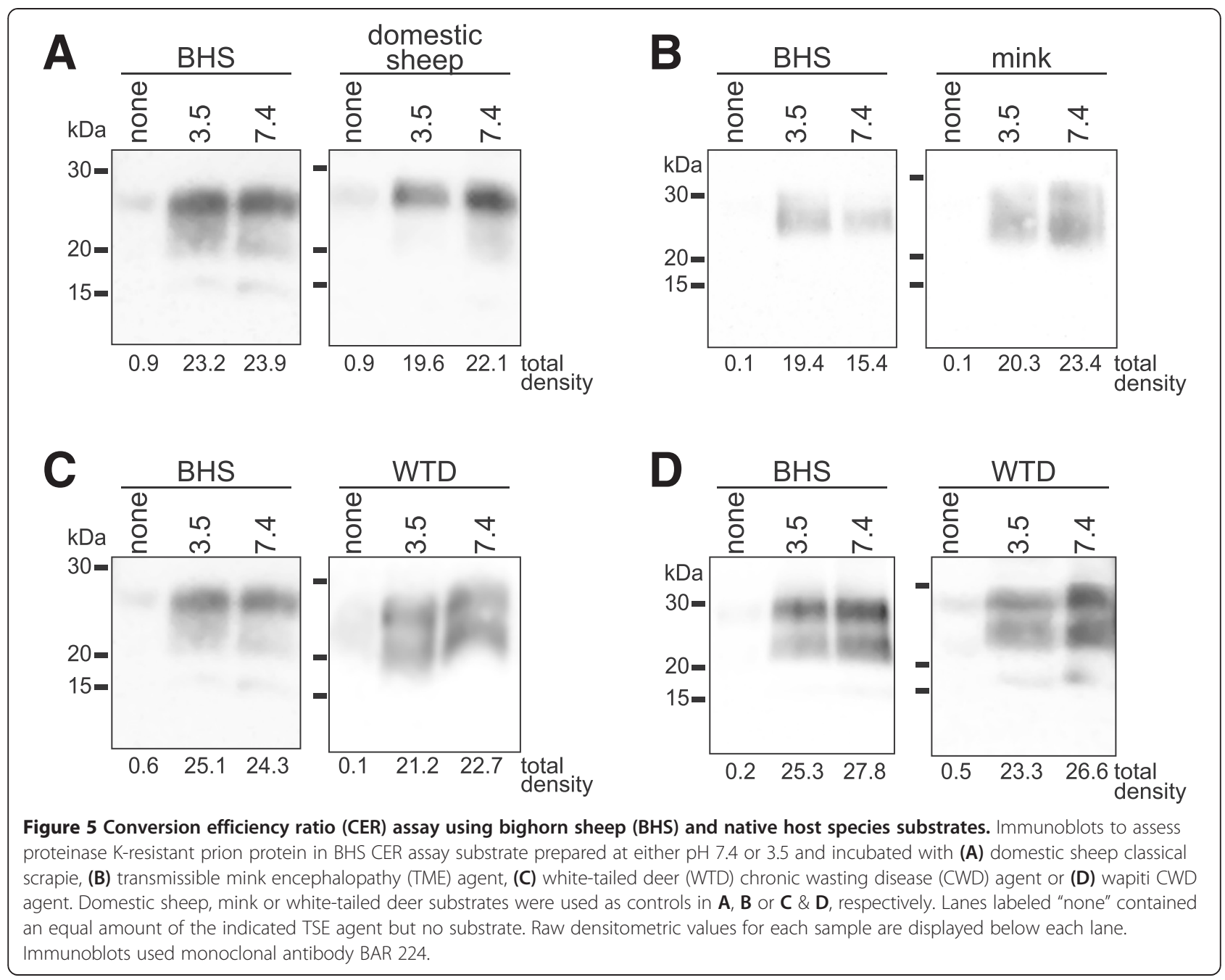

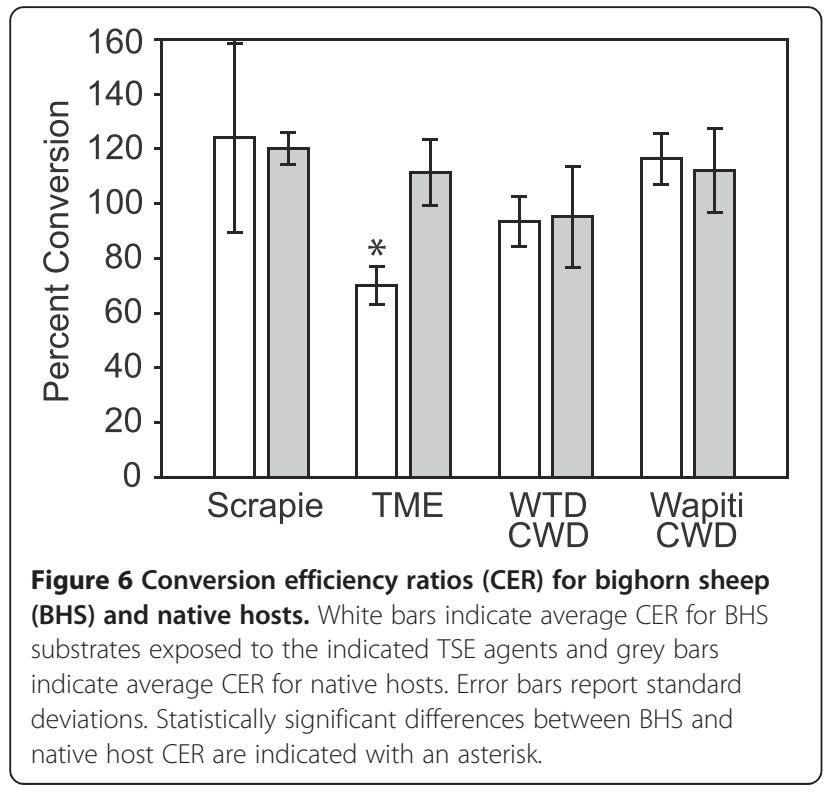

classical scrapie and CWD, and less susceptible to TME. Our present investigation and previous studies by others $[23,24]$ suggest that the CER assay can be a valuable addition to other in vitro and in vivo measures of TSE species barriers such as cell-free conversions, PMCA and animal bioassays. Advantages of the CER assay include its low cost, short experimental timeframe and replacement of living animals with tissue samples (which need not be from transgenic mice or perfused). Additionally, the assay does not use radiation, reaction conditions are identical regardless of species or strain of TSE agent and, in our hands, the CER assay is robust and forgiving. Disadvantages of the assay include poor sensitivity compared to PMCA precluding the use of CER as a means to detect $\operatorname{PrP}{ }^{\mathrm{TSE}}$, the $\mathrm{PrP}^{\mathrm{res}}$ product of conversion reactions is not known to be infectious and, importantly, the CER assay is less wellestablished than other methods of assessing species barriers which makes interpreting reductions in conversion ratios in the absence of other corroborating data difficult. For example, the correlation between a 50\% CER and TSE 
transmission parameters (e.g. disease penetrance, length of incubation period) following experimental challenge remains undefined and further work is needed to characterize this assay for use in species where bioassay data are not available. Nonetheless, in our current study we did find a similar pattern of $\mathrm{PrP}^{\text {res }}$ formation when either CER or PMCA was used for conversion. Further studies comparing the two techniques is an interesting future direction.

We are not aware of any studies examining natural transmission of scrapie from domestic sheep to BHS, but in light of the sequence identity of BHS and domestic $A^{136} R^{154} Q^{171}$ sheep prion proteins, we must consider scrapie a potential risk to BHS. Efforts to keep domestic sheep and BHS separated, as are prudent to prevent transmission of other pathogens from domestic sheep to BHS [30], are likely warranted around scrapie-infected farms. Further supporting the concept that BHS are at risk for acquiring scrapie is a report of the disease in mouflon (Ovis orientalis), another species of wild sheep [31].

In Figure 1, we show the overlap of BHS range with states and provinces known to have had scrapie cases since 2008. Reduced numbers of scrapie outbreaks in recent years, due to disease eradication efforts, may underrepresent the exposure of BHS to scrapie in years prior to 2008. Long-term environmental scrapie contamination may also still be contributing to BHS exposure to disease agent many years after scrapie outbreaks. If incubation periods of scrapie in BHS are greater than five years, exposure of BHS to pre-2008 scrapie flocks may only now have the potential to manifest as disease in BHS. The lack of current evidence for scrapie transmission to BHS could simply be due to insufficient surveillance, but other explanations, such as different susceptibilities by varying routes of exposure between domestic sheep and BHS or BHS being a "dead-end" host for scrapie, should also be explored. Sheep with Prnp genotype $\mathrm{V}^{136} \mathrm{R}^{154} \mathrm{Q}^{171}$ have been considered to be most -susceptible to classical scrapie and selective breeding efforts have focused on reducing the numbers of these animals in domestic sheep flocks across the U.S. as a scrapie risk reduction measure. Recent research, however, by Gonzalez et al. strongly suggests that Prnp genotype of the recipient sheep is not the sole factor determining its scrapie susceptibility in vivo [32]. In carrying out a series of codon 136 homologous, semi-homologous, and heterologous transmissions of two different natural scrapie isolates into domestic sheep, the study authors conclude that Prnp genotype alone cannot account for the diversity of disease phenotypes observed and that the "scrapie phenotype in sheep results from a complex interaction between source, donor and recipient factors" [32]. The susceptibility of BHS to scrapie is almost certainly dictated by this same interplay. More work is needed to explore the role of scrapie genetics on potential BHS disease transmission, as are analyses of BHS Prnp genetics using more geographically disparate samples.
The finding that white-tailed deer CWD agent could convert sheep $\operatorname{PrP}^{C}$ to $\operatorname{PrP}^{\text {res }}$ in either CER assays (Figure 6) or PMCA (Additional file 2) was notable given the sequence variations found between BHS or domestic sheep and white-tailed deer prion proteins (Figure 2), including serine to asparagine and asparagine to threonine changes in the "rigid loop" portion of the protein thought to control species susceptibility to CWD [33,34]. By CER assay, we similarly found conversion of $\mathrm{BHS} \operatorname{PrP}^{\mathrm{C}}$ by wapiti CWD heterozygous methionine/leucine at position 132. In wapiti, animals heterozygous or homozygous for leucine at prion protein amino acid $132\left(\mathrm{~L}^{132}\right)$ have a lengthened CWD incubation period [35] and $\mathrm{L}^{132}$ appears to limit CWD, but not classical scrapie, susceptibility in a transgenic mouse model [36]. Despite these amino acid mismatches, including those in the "rigid loop", the CWD agents were still effective at misfolding $\operatorname{PrP}^{C}$ from BHS. In previous studies, we have also found that voles, which have mismatches in the "rigid loop" portion of the protein, are susceptible PrP misfolding and infection by cervid CWD [37,38].

Previous work on the species barrier of sheep to CWD has been equivocal. Using cell-free conversion assays, Raymond et al. found that $\mathrm{A}^{136} \mathrm{Q}^{171}$ domestic sheep $\operatorname{PrP}^{\mathrm{C}}$ was not especially-well converted by CWD agent, but was the non-cervid substrate, among six tested species, that yielded the most $\mathrm{PrP}^{\mathrm{res}}$ [21]. In an animal study, Hamir et al. intracerebrally challenged eight domestic sheep of various Prnp genotypes with mule deer CWD [39]. One clinically-positive (heterozygous $A / V^{136} R^{154} Q^{171}$ ) and one preclinical sheep (homozygous $\mathrm{A}^{136} \mathrm{R}^{154} \mathrm{Q}^{171}$ ) were identified at the conclusion of the study, indicating that sheep can be infected by CWD, although transmission is not especially facile.

The results of our conversion assays appear to be supported by in vivo work by Béringue et al. which indicate that $\mathrm{V}^{136} \mathrm{R}^{154} \mathrm{Q}^{171}$ ovinized transgenic mice challenged with wapiti CWD harbor high levels of splenic $\operatorname{Pr} \mathrm{P}^{\text {res }}$, indicating that sheep $\operatorname{PrP}^{\mathrm{C}}$ is susceptible to misfolding by CWD agent [40]. At least one group has failed to observe clinical TSE signs in BHS when they were housed with a facility with CWD-infected animals [7]. Our results in combination with those of Béringue et al., suggest that the lack of CWD transmission to BHS was not due to inability of $\mathrm{BHS} \operatorname{PrP}^{\mathrm{C}}$ to be misfolded by CWD agent, but must derive from other factors.

In our investigation, we used white-tailed deer and wapiti CWD, but have not yet investigated $\mathrm{BHS}$ prion protein conversion by mule deer CWD. Given the sequence similarity among cervid Prnp genes and our evidence that white-tailed deer and wapiti CWD can convert BHS $\operatorname{PrP}^{\mathrm{C}}$ to $\mathrm{PrP}^{\mathrm{res}}$, we expect $\mathrm{CWD}$ from the various species to behave similarly. In a previous report, Li et al. found less $\mathrm{PrP}^{\mathrm{res}}$ generation in domestic sheep substrates when 
templated by wapiti CWD [23] than we found for BHS in our study. The genotype of the domestic sheep substrate in the previous study is unclear and differences between the sheep prion protein sequences or other species-specific differences could explain the limited conversion that they observed. Alternatively, differences in the genotypes of the wapiti CWD isolates used in the two studies could also explain variations in $\operatorname{PrP}^{\text {res }}$ levels in sheep substrates.

\section{Conclusion}

The results from our study suggest that the CER assay has the potential to be a useful tool to screen TSE species barriers. Further comparisons with PMCA and bioassays will clarify the best uses of the assay and help to define CER that are $<100 \%$. We found that BHS are unlikely to have resistance to domestic sheep classical scrapie due to their Prnp genotype. Our conversion reactions suggest that the species barrier protecting BHS from CWD may not be large and further studies, including in vivo experiments, are warranted. These animal challenge studies need not necessarily be performed in BHS, but could rather use Prnp genotype $\mathrm{A}^{136} \mathrm{R}^{154} \mathrm{Q}^{171}$ domestic sheep or existing transgenic mouse models [41]. Additionally, investigation into the susceptibility of BHS to atypical forms of scrapie is also an interesting future direction.

\section{Methods}

\section{Materials}

Chemicals and other reagents were of the highest quality possible and were from either Sigma-Aldrich (St. Louis, MO) or Fischer Scientific (Pittsburg, PA), unless otherwise specified.

\section{Tissues and disease agents}

Animal work conducted at the National Wildlife Health Center was performed under institutional animal care and use committee protocol \#EP080716. Brains from CD1 Swiss mice intracerebrally-challenged with RML-strain TSE agent and Syrian hamsters intracerebrally-challenged with 263K TSE agent were used for control experiments. Healthy Swiss Webster mouse brains were purchased from Pel-Freez Biologicals (Rogers, AR) and healthy hamster brains were obtained from unchallenged animals.

Bighorn sheep brain tissues and retropharyngeal lymph nodes were collected from 28 animals of mixed gender and age from two herds culled in the state of Washington in 2010 by the United States Department of Agriculture [42]. Sheep brain was from a clinically-ill, classical scrapie positive, Prnp $\mathrm{A}^{136} \mathrm{R}^{154} \mathrm{Q}^{171}$ genotype (Genbank accession number: AAW88328.1) ewe maintained at the University of Idaho Caine Veterinary Teaching Center. Naïve control sheep brain was from Prnp $\mathrm{A}^{136} \mathrm{R}^{154} \mathrm{Q}^{171}$ genotype ewes from a certified scrapie-free facility acquired from Ovis Sheep (Sioux
Falls, SD). Isolates of CWD from clinically-ill whitetailed deer ( $\mathrm{G}^{96}$ genotype; Genbank accession number: AF156185.1) or wapiti (heterozygous $M / L^{132}$ with other amino acids identical to Genbank accession number: ABS87888.1) were acquired from the Wisconsin Department of Natural Resources or the USGS Chronic Wasting Disease Positive Tissue Bank [43], respectively. Control white-tailed deer brain ( $\mathrm{G}^{96}$ genotype) was from a hunter-harvested animal acquired in 2010 in Vilas County, Wisconsin. Brain from a transmissible mink encephalopathy (TME)-infected mink (Neovision vision) was from an animal experimentally infected with the agent and control mink tissue was the generous gift of Dr. Maria Shank (Wisconsin Veterinary Diagnostic Laboratory). All infected brain was homogenized in phosphate buffered saline (PBS) at $10 \% \mathrm{w} / \mathrm{v}$ using separate Dounce homogenizers and stored at $-80^{\circ} \mathrm{C}$ until use. All control brains tested negative for $\mathrm{PrP}^{\mathrm{res}}$ by immunoblot.

\section{Sequence analysis}

Genomic DNA from BHS was isolated using a Genomic DNA Tissue Micro-Prep kit (Zymo Research, Irvine, CA) and was used to template PCR reactions using reagents from Marligen Biosciences (Rockville, MD) and the forward primer 5'-TACGTGGGCATATGATGCTG-3' and the reverse primer 5'-CTATCCTACTATGAGAAAAATG AG-3' specific to the extreme 5' and 3' regions of the coding sequence of the domestic sheep Prnp gene [21]. Sequencing of cervid Prnp genes was performed using published primers and protocols [44]. Amplicons were gel purified using the QIAquick gel extraction kit (Qiagen, Valencia, CA) and submitted to the University of Wisconsin Biotechnology Center for sequencing. Sequences were analyzed with Lasergene version 8.1.4 software (DNASTAR, Madison, WI). Multiple sequence alignments were performed using ClustalW2 software [45].

\section{Screening BHS tissue for preexisting TSEs}

Tissue from the obex region of the medulla oblongata of BHS was homogenized in PBS $(10 \% \mathrm{w} / \mathrm{v})$ and subjected to $\mathrm{PK}$ digestion at $50 \mu \mathrm{g} \cdot \mathrm{ml}^{-1}$ for $1 \mathrm{hr}$ at $37^{\circ} \mathrm{C}$ and subsequently prepared for NuPAGE and immunoblotting. To test the sensitivity of our immunoblot, a dilution series of $10 \%$ classical scrapie brain homogenate was prepared in $10 \%$ BHS brain homogenate, PK digested at $50 \mu \mathrm{g} \cdot \mathrm{ml}^{-1}$ for $1 \mathrm{hr}$ at $37^{\circ} \mathrm{C}$ and prepared for NuPAGE and immunoblotting. Retropharyngeal lymph nodes from BHS were analyzed at the Wisconsin Veterinary Diagnostic Laboratory using the TeSeE ELISA kit and standard procedures (BioRad, Hercules, CA). Brains from BHS used for conversion efficiency ratio assay substrates were also screened using PMCA as described in the PMCA section. 
Conversion efficiency ratio (CER) assay substrate preparation Uninfected brain homogenate used in the in vitro conversion assay was prepared using the method described in Zou et al. [24]. Briefly, brain tissue was homogenized at $10 \% \mathrm{w} / \mathrm{v}$ in cell lysis buffer $(100 \mathrm{mM} \mathrm{NaCl}, 10 \mathrm{mM}$ EDTA, 0.5\% NP-40, 0.5\% deoxycholate, $10 \mathrm{mM}$ Tris $\mathrm{pH} 7.5$ ). Guanidine $\mathrm{HCl}(3 \mathrm{M})$ in $\mathrm{PBS}$ at either $\mathrm{pH} 3.5$ or 7.4 was added to the homogenate at a 1:1 ratio and gently rotated at room temperature for $5 \mathrm{hr}$. Protein was then precipitated with 4 volumes of methanol at $-20^{\circ} \mathrm{C}$ for $16-18 \mathrm{hr}$ and sedimented by centrifugation at $13,000 \mathrm{~g}$ for $30 \mathrm{~min}$ at $4^{\circ} \mathrm{C}$. Pellets were resuspended in conversion buffer (0.05\% SDS, $0.5 \%$ Triton X-100 in PBS at pH 7.4), briefly sonicated in a cuphorn sonicator, and the resultant conversion assay substrate was stored at $-80^{\circ} \mathrm{C}$ until use.

\section{Conversion efficiency reactions}

Conversion reactions were performed in $200 \mu \mathrm{l}$ MAXY Mum Recovery low binding PCR Tubes (Axygen Scientific, Union City, CA) by adding $5 \mu \mathrm{l}$ of $10 \%$ infected brain homogenate to $95 \mu \mathrm{l}$ of uninfected brain substrate that was previously denatured at either $\mathrm{pH} 3.5$ or 7.4 as described earlier. Control samples lacking brain substrate contained only TSE agent and conversion buffer. Tubes were vortexed briefly then placed in a 96-well PCR tube thermo-shaker (Hangzhou All Sheng Instruments, Hangzhou City, Zhejiang Province, China) for $24 \mathrm{hr}$ at $37^{\circ} \mathrm{C}$ at $1000 \mathrm{rpm}$. After shaking, reactions were treated with sarkosyl to a final concentration of $2 \% \mathrm{w} / \mathrm{v}$ and digested with PK $\left(100 \mu \mathrm{g} \cdot \mathrm{ml}^{-1}\right)$ for $1 \mathrm{hr}$ at $37^{\circ} \mathrm{C}$. We found that adding sarkosyl to samples post-incubation aided PK digestion of prion protein in unseeded substrates (data not presented). Samples were then prepared for NuPAGE and immunoblotting. Assays with BHS substrate were performed using at least two individual animals and all assays were individually replicated at least three times.

\section{Protein misfolding cyclic amplification (PMCA)}

Procedures for PMCA were based on those previously published for domestic sheep [46]. Briefly, PMCA substrates were prepared from uninfected $A^{136} R^{154} Q^{171}$ genotype domestic sheep or BHS medullas homogenized to $10 \% \mathrm{w} / \mathrm{v}$ using Dounce homogenizers in ice-cold conversion buffer composed of PBS with $150 \mathrm{mM} \mathrm{NaCl}, 1 \%$ Triton X-100, 4 mM EDTA and mini-Complete protease inhibitor (Roche, Indianapolis, IN) at $\mathrm{pH}$ 7.4. Classical scrapie, white-tailed deer CWD or TME agents were diluted into the domestic sheep substrate at dilution factors of $10^{-2}$ or $10^{-3}$ of a $10 \%$ w/v brain homogenate. Substrate from BHS was left unseeded to test for pre-existing $\operatorname{PrP}^{\mathrm{Sc}}$. Samples were either frozen at $-80^{\circ} \mathrm{C}$ or immediately subjected to PMCA with bead enhancement [47]. Samples for PMCA were sonicated for $48 \mathrm{~h}$ at $37^{\circ} \mathrm{C}$ using cycles composed of a pulse at $80 \%$ amplitude for $20 \mathrm{~s}$ followed by $30 \mathrm{~min}$ of incubation.
Samples for serial PMCA were reseeded into fresh BHS substrate at a 1:10 ratio. After PMCA, some samples were digested with $\mathrm{PK}\left(100 \mu \mathrm{g} \cdot \mathrm{ml}^{-1}\right)$ for $1 \mathrm{hr}$ at $37^{\circ} \mathrm{C}$ prior to immunoblotting. Experiments were independently replicated twice and negative control samples lacking TSE agents were subjected to PMCA and were included in each experiment.

\section{NuPAGE and immunoblotting}

Prior to NuPAGE, lithium dodecyl sulfate sample buffer and NuPAGE reducing agent (both from Invitrogen, Carlsbad, CA) were added to samples to a final concentration of $1 \times$. Samples were then heated at $95^{\circ} \mathrm{C}$ in a dry block heater for $5 \mathrm{~min}$, cooled and loaded into 12\% Bis-Tris NuPAGE gels. Proteins were transferred to polyvinyldifluoride membranes (Immobilon-P, Millipore, Billerica, MA), blocked in non-fat dry milk and immunoblotted using SAF 83 or BAR 224 monoclonal antibodies (Cayman Chemical, Ann Arbor, MI) at a 1:5,000 dilution and polyclonal goat anti-mouse IgG (Santa Cruz Biotechnology, Santa Cruz, CA) at a 1:10,000 dilution. Immunoreactivity was detected using SuperSignal West Pico chemiluminescent system (Thermo Scientific Pierce Chemical, Rockford, IL) and an EC3 imaging system (UVP, Upland, CA). For presentation purposes, some irrelevant lanes were excised from images of membranes and no further changes to brightness or contrast were made following excision. Data from separate gels presented in the same figure are presented in separate boxes.

\section{Calculation of conversion efficiency ratio (CER)}

Substrates at $\mathrm{pH} 7.4$ and 3.5, which were prepared at the same time from the same brain homogenate starting material, were incubated and shaken with a TSE agent, PK treated, ran on the same gel and immunoblotted together. Levels of $\mathrm{PrP}^{\text {res }}$ were measured by densitometry using the VisionWorks LS software on the EC3 imaging system. The density of the $\mathrm{pH} 7.4$ sample was divided by the density of the $\mathrm{pH} 3.5$ sample and multiplied by 100 to produce a percentage. Data from replicates of experiment were compiled to generate a mean CER for a species with a given TSE agent \pm standard deviation. An analysis of variance was performed using the Tukey-Kramer minimum significance differences method and Student's $t$ test performed with GraphPad software (La Jolla, CA).

\section{Additional files}

Additional file 1: Bighorn sheep (BHS) and native host conversion efficiency ratios substrates. Substrates prepared at either $\mathrm{pH} 7.4$ or 3.5 from BHS, mink, domestic sheep or white-tailed deer (WTD) were shaken in the absence of TSE agents. No proteinase K-resistant prion protein was found by immunoblot with monoclonal antibody BAR 224.

Additional file 2: Protein misfolding cyclic amplification (PMCA) using domestic sheep $\left(A^{136} R^{154} Q^{171}\right)$ genotype substrate. The indicated TSE agents were diluted to $10^{-2}$ or $10^{3}$ from $10 \% \mathrm{~W} / \mathrm{V}$ stocks of 
brain homogenate into domestic sheep PMCA substrate and subjected to 96 cycles of sonication. Proteinase K (PK)-resistant prion protein levels were assessed by immunoblotting with monoclonal antibody BAR 224 . As a control, substrate without TSE agent seed was subjected to PMCA cycling. Samples of sheep substrate containing the indicated TSE agents, but not subjected to PMCA, served to establish background levels of PK-resistant prion protein.

\section{Abbreviations}

TSE: Transmissible spongiform encephalopathy; CWD: Chronic wasting disease; BHS: Bighorn sheep (Ovis canadensis); Prnp: Gene encoding the prion protein; $\operatorname{PrP}{ }^{C}$ : Normal cellular prion protein; $\operatorname{PrP}^{T S E}$ : Disease-associated prion protein; PK: Proteinase K; PrPres: Proteinase K-resistant prion protein; PMCA: Protein misfolding cyclic amplification; CER: Conversion efficiency ratio; TME: Transmissible mink encephalopathy; PBS: Phosphate buffered saline.

\section{Competing interests}

The authors declare that they have no competing interests.

\section{Authors' contributions}

ARM, CMC and HC performed experiments, analyzed results and helped draft the manuscript. CJJ conceived of the study, performed experiments, analyzed results and helped draft the manuscript. All authors have read and approved the final version of the manuscript.

\section{Acknowledgments}

We would like to thank Prof. Neil Cashman and Dr. Li Li (University of British Columbia) for assistance in adapting their conversion assay for our own application, Dr. Delwyn Keane and Ben Johnson (Wisconsin Veterinary Diagnostic Laboratory) for technical support with ELISA analyses, Prof. Joel Pedersen (University of Wisconsin) for the generous use of his laboratory space during the remodeling of the NWHC and Dr. Chad Johnson (University of Wisconsin) for assistance with sequencing Prnp genes. We are also very grateful to Dr. Thomas DeLiberto (US Department of Agriculture), Prof. Debbie McKenzie (University of Alberta), Dr. Krysten Schuler (Cornell University), Nathan Ramsay (NWHC), Sharon Sorenson (University of Idaho), Dr. Maria Shank (Wisconsin Veterinary Diagnostic Laboratory) and Maxine Drager for assistance with acquiring tissues. We appreciate the constructive comments of Dr. Daniel Walsh, Nicole Gibbs and Dr. Dennis Heisey. This work was funded by USGS Wildlife: Terrestrial and Endangered Resources Program. The funding organization did not influence study design, collection and analysis of data or the decision to publish. Any use of trade, product, or firm names is for descriptive purposes only and does not imply endorsement by the U.S. Government.

\section{Author details}

'Department of Bacteriology, University of Wisconsin, Madison, WI, USA. ${ }^{2}$ USGS National Wildlife Health Center, Madison, WI, USA. ${ }^{3}$ Program in Cellular and Molecular Biology, University of Wisconsin, Madison, WI, USA. ${ }^{4}$ Present address: National Institutes of Health, 9000 Rockville Pike, Bethesda 20892, Maryland, USA.

Received: 1 May 2013 Accepted: 2 August 2013

Published: 9 August 2013

\section{References}

1. Valdez R, Krausman PR: Mountain sheep of North America. Tucson: University of Arizona Press; 1999.

2. Shackleton DM: Ovis canadensis. Mamm Species 1985, 230:1-9.

3. Singer FJ, Moses ME, Bellew S, Sloan W: Correlates to colonizations of new patches by translocated populations of bighorn sheep. Restor Ecol 2000, 8(4):66-74.

4. Foreyt WJ, Snipes KP, Kasten RW: Fatal pneumonia following inoculation of healthy bighorn sheep with Pasteurella haemolytica from healthy domestic sheep. J Wildlife Dis 1994, 30(2):137-145.

5. George JL, Martin DJ, Lukacs PM, Miller MW: Epidemic pasteurellosis in a bighorn sheep population coinciding with the appearance of a domestic sheep. J Wildlife Dis 2008, 44(2):388-403.

6. Lawrence PK, Shanthalingam S, Dassanayake RP, Subramaniam R, Herndon CN, Knowles DP, Rurangirwa FR, Foreyt WJ, Wayman G, Marciel AM, et al:
Transmission of Mannheimia haemolytica from domestic sheep (Ovis aries) to bighorn sheep (Ovis canadensis): unequivocal demonstration with green fluorescent protein-tagged organisms. J Wildifie Dis 2010, 46(3):706-717.

7. Williams ES, Barker IK: Infectious diseases of wild mammals, Volume 3. Ames: lowa State University Press; 2001.

8. Watts JC, Balachandran A, Westaway D: The expanding universe of prion diseases. PLoS Pathog 2006, 2(3):e26.

9. Detwiler LA, Baylis M: The epidemiology of scrapie. Rev Sci Tech Off Int Epiz 2003, 22(1):121-143.

10. Sigurdson CJ: A prion disease of cervids: chronic wasting disease. Vet Res 2008, 39(4):41.

11. Williams ES, Young S: Spongiform encephalopathies in Cervidae. Rev Sci Tech Off Int Epiz 1992, 11(2):551-567.

12. Annual Big Game Herd Unit Reports. http://wgfd.wyo.gov/web2011/ Departments/Wildlife/pdfs/JCR_BGCASPERCOMP_20110002864.pdf

13. Gough KC, Maddison BC: Prion transmission: prion excretion and occurrence in the environment. Prion 2010, 4(4):275-282.

14. Georgsson G, Sigurdarson S, Brown P: Infectious agent of sheep scrapie may persist in the environment for at least 16 years. J Gen Virol 2006, 87(12):3737-3740.

15. Miller MW, Williams ES, Hobbs NT, Wolfe LL: Environmental sources of prion transmission in mule deer. Emerg Inf Dis 2004, 10(6):1003-1006.

16. Colby DW, Prusiner SB: Prions. Cold Spring Harb Perspect Biol 2011, 3(1). doi:10.1101/cshperspect.a006833

17. Bolton DC, MCKinley MP, Prusiner SB: Identification of a protein that purifies with the scrapie prion. Science 1982, 218(4579):1309-1311.

18. Kubler E, Oesch B, Raeber AJ: Diagnosis of prion diseases. British Med Bull 2003, 66:267-279.

19. Beringue $V$, Vilotte $J$, Laude $H$ : Prion agent diversity and species barrier. Vet Res 2008, 39(4):47.

20. Kocisko DA, Priola SA, Raymond GJ, Chesebro B, Lansbury PT Jr, Caughey B: Species specificity in the cell-free conversion of prion protein to protease-resistant forms: a model for the scrapie species barrier. Proc Natl Acad Sci USA 1995, 92(9):3923-3927.

21. Raymond GJ, Bossers A, Raymond LD, O'Rourke KI, McHolland LE, Bryant PK 3rd, Miller MW, Williams ES, Smits M, Caughey B: Evidence of a molecular barrier limiting susceptibility of humans, cattle and sheep to chronic wasting disease. EMBO J 2000, 19(17):4425-4430.

22. Fernandez-Borges N, de Castro J, Castilla J: In vitro studies of the transmission barrier. Prion 2009, 3(4):220-223.

23. Li L, Coulthart MB, Balachandran A, Chakrabartty A, Cashman NR: Species barriers for chronic wasting disease by in vitro conversion of prion protein. Biochem Biophys Res Commun 2007, 364(4):796-800.

24. Zou WQ, Cashman NR: Acidic $\mathrm{pH}$ and detergents enhance in vitro conversion of human brain $\mathrm{PrP}^{\mathrm{C}}$ to a PrP ${ }^{\mathrm{SC}}$-like form. J Biol Chem 2002, 277(46):43942-43947.

25. van Keulen L, Schreuder BE, Meloen RH, Mooij-Harkes G, Vromans ME, Langeveld JP: Immunohistochemical detection of prion protein in lymphoid tissues of sheep with natural scrapie. J Clin Microbiol 1996 34(5):1228-1231.

26. Groschup MH, Buschmann A: Rodent models for prion diseases. Vet Res 2008, 39(4):32.

27. Chandler RL: Encephalopathy in mice produced by inoculation with scrapie brain material. Lancet 1961, 277(7191):1378-1379.

28. Browning SR, Mason GL, Seward T, Green M, Eliason GA, Mathiason C, Miller MW, Williams ES, Hoover E, Telling GC: Transmission of prions from mule deer and elk with chronic wasting disease to transgenic mice expressing cervid PrP. J Virol 2004, 78(23):13345-13350.

29. Hadlow WJ, Race RE, Kennedy RC: Experimental infection of sheep and goats with transmissible mink encephalopathy virus. Can J Vet Res 1987, 51(1):135-144.

30. Schommer TJ, Woolever MW: A review of disease related conflicts between domestic sheep and goats and bighorn sheep. In RMRS-GTR-209. Fort Collins, CO: US Department of Agriculture, Forest Service, Rocky Mountains Research Station; 2008.

31. Wood JL, Lund L, Done SH: The natural occurrence of scrapie in moufflon. Vet Rec 1992, 130(2):25-27.

32. Gonzalez L, Jeffrey M, Dagleish MP, Goldmann W, Siso S, Eaton SL, Martin S, Finlayson J, Stewart P, Steele P, et al: Susceptibility to scrapie and disease phenotype in sheep: cross-PRNP genotype experimental transmissions with natural sources. Vet Res 2012, 43(1):55. 
33. Kurt TD, Telling GC, Zabel MD, Hoover EA: Trans-species amplification of $\operatorname{PrP}(C W D)$ and correlation with rigid loop 170N. Virology 2009, 387(1):235-243.

34. Sigurdson CJ, Nilsson KP, Hornemann S, Manco G, Fernandez-Borges N, Schwarz P, Castilla J, Wuthrich K, Aguzzi A: A molecular switch controls interspecies prion disease transmission in mice. J Clin Invest 2010, 120(7):2590-2599.

35. Hamir AN, Gidlewski T, Spraker TR, Miller JM, Creekmore L, Crocheck M, Cline T, O'Rourke KI: Preliminary observations of genetic susceptibility of elk (Cervus elaphus nelsoni) to chronic wasting disease by experimental oral inoculation. J Vet Diag Invest 2006, 18(1):110-114.

36. Green KM, Browning SR, Seward TS, Jewell JE, Ross DL, Green MA, Williams ES, Hoover EA, Telling GC: The elk PRNP codon 132 polymorphism controls cervid and scrapie prion propagation. J Gen Virol 2008, 89(2):598-608.

37. Kurt TD, Seelig DM, Schneider JR, Johnson CJ, Telling GC, Heisey DM, Hoover EA: Alteration of the chronic wasting disease species barrier by in vitro prion amplification. J Virol 2011, 85(17):8528-8537.

38. Heisey DM, Mickelsen NA, Schneider JR, Johnson CJ, Langenberg J, Bochsler PN, Keane DP, Barr DJ: Chronic wasting disease susceptibility of four North American rodents. J Virol 2010, 84(1):210-215.

39. Hamir AN, Kunkle RA, Cutlip RC, Miller JM, Williams ES, Richt JA: Transmission of chronic wasting disease of mule deer to Suffolk sheep following intracerebral inoculation. J Vet Diag Invest 2006, 18(6):558-565.

40. Beringue V, Herzog L, Jaumain E, Reine F, Sibille P, Le Dur A, Vilotte JL, Laude H: Facilitated cross-species transmission of prions in extraneural tissue. Science 2012, 335(6067):472-475.

41. Arsac JN, Betemps D, Morignat E, Feraudet C, Bencsik A, Aubert D, Grassi J, Baron T: Transmissibility of atypical scrapie in ovine transgenic mice: major effects of host prion protein expression and donor prion genotype. PLoS One 2009, 4(10):e7300.

42. Washington Wildlife Officials To Cull Bighorn Sheep Herd For Disease. http://news.opb.org/article/washington-wildlife-officials-cull-bighorn-sheepherd-disease/

43. Chronic Wasting Disease Positive Tissue Bank. http://www.nwhc.usgs.gov/ publications/fact_sheets/pdfs/cwd/CWDTissueBank.pdf

44. Johnson C, Johnson J, Vanderloo JP, Keane D, Aiken JM, McKenzie D: Prion protein polymorphisms in white-tailed deer influence susceptibility to chronic wasting disease. J Gen Virol 2006, 87(7):2109-2114.

45. Larkin MA, Blackshields G, Brown NP, Chenna R, McGettigan PA, McWilliam $H$, Valentin F, Wallace IM, Wilm A, Lopez R, et al: Clustal W and Clustal X version 2.0. Bioinformatics 2007, 23(21):2947-2948.

46. Bucalossi C, Cosseddu G, D'Agostino C, Di Bari MA, Chiappini B, Conte M, Rosone F, De Grossi L, Scavia G, Agrimi U, et al: Assessment of the genetic susceptibility of sheep to scrapie by protein misfolding cyclic amplification and comparison with experimental scrapie transmission studies. J Virol 2011, 85(16):8386-8392.

47. Gonzalez-Montalban N, Makarava N, Ostapchenko VG, Savtchenk R, Alexeeva I, Rohwer RG, Baskakov IV: Highly efficient protein misfolding cyclic amplification. PLoS Pathog 2011, 7(2):e1001277.

doi:10.1186/1746-6148-9-157

Cite this article as: Morawski et al: In vitro prion protein conversion suggests risk of bighorn sheep (Ovis canadensis) to transmissible spongiform encephalopathies. BMC Veterinary Research 2013 9:157.

\section{Submit your next manuscript to BioMed Central and take full advantage of:}

- Convenient online submission

- Thorough peer review

- No space constraints or color figure charges

- Immediate publication on acceptance

- Inclusion in PubMed, CAS, Scopus and Google Scholar

- Research which is freely available for redistribution

Submit your manuscript at www.biomedcentral.com/submit 